\title{
Diabetes-Specific Nutrition Algorithm: A Transcultural Program to Optimize Diabetes and Prediabetes Care
}

\author{
Jeffrey I. Mechanick • Albert E. Marchetti • \\ Caroline Apovian • Alexander Koglin Benchimol • \\ Peter H. Bisschop • Alexis Bolio-Galvis • \\ Refaat A. Hegazi • David Jenkins • Enrique Mendoza • \\ Miguel Leon Sanz • Wayne Huey-Herng Sheu • \\ Patrizio Tatti • Man-Wo Tsang • Osama Hamdy \\ Published online: 10 February 2012 \\ (C) The Author(s) 2012. This article is published with open access at Springerlink.com
}

\begin{abstract}
Type 2 diabetes (T2D) and prediabetes have a major global impact through high disease prevalence, significant downstream pathophysiologic effects, and enormous financial liabilities. To mitigate this disease burden,
\end{abstract}

J. I. Mechanick $(\bowtie)$

Division of Endocrinology, Diabetes, and Bone Disease,

Mount Sinai School of Medicine,

New York, NY, USA

e-mail: jeffreymechanick@gmail.com

\section{A. E. Marchetti}

Department of Preventive Medicine and Community Health,

University of Medicine and Dentistry of New Jersey,

Newark, NJ, USA

\section{Apovian}

Nutrition and Weight Management Center,

Boston University School of Medicine,

Boston, MA, USA

\section{A. K. Benchimol}

Obesity and Eating Disorders Group, State Institute of Diabetes and Endocrinology of Rio de Janeiro,

Rio de Janeiro, Brazil

\section{P. H. Bisschop}

Division of Endocrinology and Metabolism,

Academic Medical Center, University of Amsterdam,

Amsterdam, The Netherlands

\section{A. Bolio-Galvis}

Department of General and Bariatric Surgery and Clinical Nutrition, Hospital Angeles Pedregal; Clinical Nutrition and General Surgery, Facultad Mexicana de Medicina, Universidad La Salle, México City, Mexico

\section{R. A. Hegazi}

Research \& Development, Abbott Nutrition,

Columbus, OH, USA interventions of proven effectiveness must be used. Evidence shows that nutrition therapy improves glycemic control and reduces the risks of diabetes and its complications. Accordingly, diabetes-specific nutrition therapy should be incorporated

\section{Jenkins}

Department of Nutritional Sciences, University of Toronto,

Toronto, Ontario, Canada

\section{E. Mendoza}

University of Panama School of Medicine,

Panama City, Panama

\section{L. Sanz}

Service of Endocrinology and Nutrition,

University Hospital Doce de Octubre, Department of Medicine,

Complutense University, Madrid, Spain

\section{W. H.-H. Sheu}

Division of Endocrinology and Metabolism, Taichung Veterans General Hospital, Taichung; College of Medicine,

Chung-Shan Medical University, Taichung; School of Medicine, National Yang-Ming Medical University,

Taipei, Taiwan

\section{P. Tatti}

Department of Endocrinology and Diabetology, ASL RMH,

Rome, Italy

M.-W. Tsang

Division of Diabetes \& Endocrinology, Department of Medicine \& Geriatrics, United Christian Hospital, Hospital Authority,

Hong Kong, China

O. Hamdy

Division of Endocrinology, Diabetes and Metabolism,

Joslin Diabetes Center, Harvard Medical School,

Boston, MA, USA 
into comprehensive patient management programs. Evidence-based recommendations for healthy lifestyles that include healthy eating can be found in clinical practice guidelines (CPGs) from professional medical organizations. To enable broad implementation of these guidelines, recommendations must be reconstructed to account for cultural differences in lifestyle, food availability, and genetic factors. To begin, published CPGs and relevant medical literature were reviewed and evidence ratings applied according to established protocols for guidelines. From this information, an algorithm for the nutritional management of people with T2D and prediabetes was created. Subsequently, algorithm nodes were populated with transcultural attributes to guide decisions. The resultant transcultural diabetes-specific nutrition algorithm (tDNA) was simplified and optimized for global implementation and validation according to current standards for $\mathrm{CPG}$ development and cultural adaptation. Thus, the tDNA is a tool to facilitate the delivery of nutrition therapy to patients with T2D and prediabetes in a variety of cultures and geographic locations. It is anticipated that this novel approach can reduce the burden of diabetes, improve quality of life, and save lives. The specific Southeast Asian and Asian Indian tDNA versions can be found in companion articles in this issue of Current Diabetes Reports.

Keywords Diabetes · Diet - Glycemic control - Nutrition . Transcultural $\cdot$ Prediabetes

\section{Introduction}

Type 2 diabetes (T2D) and prediabetes impose a huge burden of illness on developed and developing nations through high disease prevalence $(6.6 \%$ overall, $>10 \%$ in many countries), direct and indirect multisystem pathophysiologic effects, and financial liabilities (US\$376 billion annually worldwide) [1]. This enormous disease burden can be reduced by deliberate application of interventions with proven effectiveness [2-14]. Ideally, diagnostic and therapeutic interventions should be accessible, facile, affordable, costeffective, and culturally sensitive [1]. To improve efficiency, they can be combined in coordinated disease management programs. Lifestyle management, including physical activity and diabetes-specific nutrition therapy, is an essential and necessary component of any comprehensive care plan for diabetes $[15 \bullet \bullet, 16,17]$. Care plan implementation is facilitated by clinical practice guidelines (CPGs) intended to inform clinical decisions, standardize and optimize patient care, improve outcomes, and control costs [18, 19]. Recommendations within CPGs should be evidence-based, precise, clear, relevant, authoritative, and compatible with existing norms $[20,21 \bullet \cdot$. The purpose of this report is to describe pertinent background material and the development process of a transcultural diabetes-specific nutrition algorithm (tDNA) that can facilitate portability of evidencebased recommendations to better enable their implementation and validation across a broad geographic and cultural spectrum.

\section{Benefits and Problems Associated with CPGs}

Although CPGs may have distinct flaws or problems intrinsic to their development, interpretation, and implementation, they are useful tools to aid clinical decision making and improve patient care $[21 \bullet \bullet, 22-26]$. Benefits are derived from the characteristics and attributes of the CPGs. For example, authoritative guidelines are developed by expert panels from specialized areas of medicine and reflect group consensus on specific aspects of patient care. These CPGs are evidencebased, transparently incorporating relevant research findings, and contain recommendations with the greatest potential for superior clinical outcomes. Depending on the methodology used, CPGs may consider subjective factors such as risk-benefit perceptions and costeffectiveness. They may also engage such principles as middle-range question-oriented literature searching, patientoriented evidence, cascades of recommendations for a particular clinical question based on variations in clinical settings, multiple levels of review, and diligent screening of writers and reviewers with respect to credentialing and conflicts of interest [21••]. Through these exacting methodologies and resultant credible content, CPGs empower practitioners, patients, and the larger universe of other health care stakeholders to make better decisions regarding the applicability of care.

CPGs also have limitations [1, 19, 27]. Even if their recommendations are appropriate, their implementation and performance can be impeded by untimeliness, complexity, and/or incompatibility with other recommendations. Their adoption and adherence may be further hindered by idiosyncratic physician and patient attitudes as well as the unique characteristics of a practice setting [28]. Guidelines may not accommodate disruptions in the continuity of care that arise among health care providers, facilities, and time frames [29]. Moreover, selected recommendations may reflect only a professional perspective, which may discount patient predilections or values and compromise clinical adherence and outcomes [19, 28]. Finally, CPGs may not be able to be generalized for all patients or populations. Patient age, gender, and genomics, as well as culture, customs, and environment, must be factored into any decision to apply a particular recommendation to a particular patient in a particular 
setting [29]. In effect, CPGs are simply not portable across divergent clinical settings. In light of the globalization and impact of the diabetes epidemic, this significant problem must be resolved.

\section{Addressing the Portability Problem}

Whenever possible, either de novo or the most recent up-todate CPGs on a particular topic should be used as a resource for specific patient management issues [30]. For ease of implementation, the CPGs should be straightforward and readily understood [20]. Derivative products (i.e., decision trees, flow charts, or algorithms) can be used to reduce the complexity of comprehensive CPGs, aid comprehension, and facilitate successful implementation and validation [31-33]. Such tools not only improve the standardization of care, but also help to coordinate the activities of all members of a treatment team for patients with diabetes. A diabetes flow sheet was shown to increase CPG adherence in a recent outcomes study based on medical audits [34].

\section{Transcultural Factors}

To address the problem of generalizability and the effect of cultural differences among patients on a global scale, CPG development must begin with a robust decision-tree template amenable to strategic modification that does not sacrifice performance. Thus, the tDNA template was designed for the optimization of nutritional care for patients with T2D and prediabetes on a global scale (Fig. 1, Tables 1, 2, 3, 4, 5,

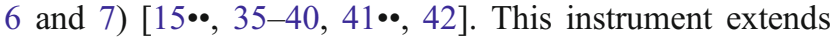
evidence-based nutritional recommendations from the American Association of Clinical Endocrinologists (AACE) $[15 \bullet \cdot, 43]$ and the American Diabetes Association (ADA) $[41 \bullet \cdot]$ and provides nodes that can be populated with information based on geographic and ethnocultural factors for individualization and implementation at regional and local levels worldwide. The tDNA is intended to 1) increase awareness of the benefits of nutritional interventions for patients with T2D and prediabetes; 2) encourage healthy dietary patterns that accommodate regional differences in genetic factors, lifestyles, foods, and cultures; 3) enhance the implementation of existing CPGs for T2D and prediabetes management; and 4) simplify nutritional therapy for ease of application and portability.

\section{Methodology to Develop the tDNA}

The methods and procedures used to develop the tDNA are widely recognized as state-of-the-art within medical organizations and were rigorously applied throughout this endeavor. The task force chair initiated the project via live meetings and telephone or digital communications. Internationally respected health care experts in diabetes and nutrition from Brazil, Canada, China, Mexico, The Netherlands, Panama, Spain, Taiwan, and the United States were identified through literature searches and peer recommendations. Each expert was contacted, briefed on the project, and questioned about his or her current activities and interest in participating in the program. Based on responses, invitations were extended until a complement of specialists, sufficient for advisory activities, accepted the request to be included in the task force.

Members of the task force provided data, culturally meaningful information, and expert opinion to guide algorithm development. During a meeting in New York City on November 12 to 13,2010 , members discussed clinical evidence and the influence of various diabetes risk factors and comorbidities (cardiovascular events, obesity, hypertension, and dyslipidemia) in the construction of the tDNA template. Task force members also deliberated over the relative merits of specific metrics (body weight, waistto-hip ratio [WHR], fasting blood glucose, and glycosylated hemoglobin $\left[\mathrm{HbA}_{1 \mathrm{c}}\right]$ ) and nutritional therapies (foods, diets, and calorie supplementation and replacement with prepared diabetes-specific formulas) that would be cited in the template. Diabetes-specific formulas (glycemia-targeted specialized nutrition formulas) may be used for calorie replacement or supplementation as part of medical nutrition therapy (MNT). Transcultural factors influencing dietary practices, food choices, and diabetes health care interventions were also considered. For example, energy-dense fast foods are ubiquitous but may take different forms throughout the world. Likewise, healthy foods take different forms based on geography and seasonality. Table 8 lists common international foods and their glycemic indices [44]. Such information becomes essential at the local level to make nutritional therapy meaningful.

The evidence supporting task force recommendations was rated and assigned a numerical descriptor according to levels of scientific substantiation provided by the 2010 AACE protocol for the development of CPGs (Table 9) $[21 \bullet \bullet$. The cumulative information was then codified using an alphabetic descriptor (grade A, B, C, D), reflecting the respective strength of the recommendation $[21 \bullet \bullet]$. The data and information used to construct the algorithm, as well as the included recommendations, closely reflect similar information and grading found in the diabetes nutrition sections

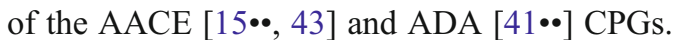

Following the initial task force meeting, a subcommittee reviewed a meeting transcript to adopt points of agreement and resolve points of disagreement to achieve consensus on all major topics of discussion. Subsequently, all task force members received abstract summaries of the proceedings for their 
(1)

Ethno-cultural lifestyle input

1) Geographic location and 2) ethno-cultural classification

(2)

Individual risk stratification
Family history of high-risk dietary patterns and premature cardiovascular disease,

less than recommended physical activity, abnormal anthropometrics

(BMI/WC/WHR over normal ranges for locale), hypertension, dyslipidemia,

any cardiovascular event, any liver disease, microalbuminuria over normal range, risky

alcohol intake, any sleep disturbance, any chronic illness

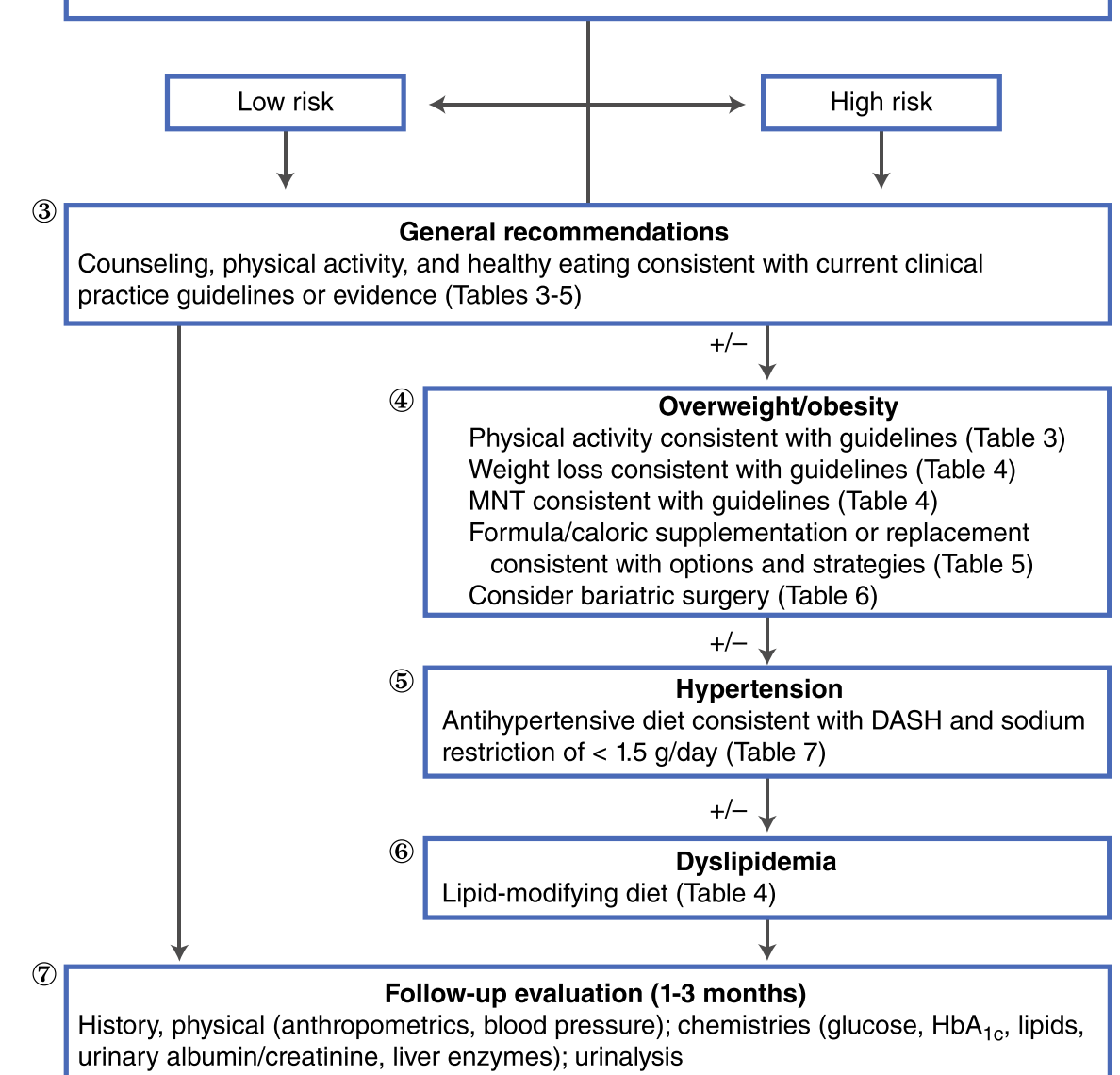

Prediabetes is established by: IFG $=100-125 \mathrm{mg} / \mathrm{dL}$;

IGT $=140-199 \mathrm{mg} / \mathrm{dL} ;$ and $/$ or $\mathrm{HbA}_{1 \mathrm{c}}=5.7 \%-6.4 \%$,

Diabetes is established by: $F P G \geq 126 \mathrm{mg} / \mathrm{dL}$;

casual $\mathrm{PG} \geq 200 \mathrm{mg} / \mathrm{dL}$; 2 -hour $0 \mathrm{GTT} \geq 200 \mathrm{mg} / \mathrm{dL}$;

$\mathrm{HbA}_{1 \mathrm{c}} \geq 6.5 \%$. ( $\mathrm{HbA}_{1 \mathrm{c}}$ alone is not recommended

to diagnose diabetes).

Location, ethnicity, and culture individualize recommendations. Inputs will inform other areas of the algorithm.

Anthropometrics include weight, BMI, WC, and/or WHR according to local preference/custom. See body composition parameters in Tables 1 and 2 .

Excessive daily alcohol consumption is defined as $>2$ drinks for men and $>1$ drink for women.

Individual risk stratification directs lifestyle interventions for improved glycemic control and decreased risks for progression, complications, and mortality.

Insufficient physical activity is $<30 \mathrm{~min} /$ day and/or $<5$ days/week.

Low-risk patients with prediabetes or type 2 diabetes have no adverse conditions other than an impaired glycemic profile and should follow established general recommendations for lifestyle interventions plus nutritional therapy per AACE/ADA guidelines. High-risk patients have $\geq 1$ risk factors that require specific interventions to reduce progression, complications, and mortality. Conditions amenable to lifestyle change include overweight/obesity, hypertension, and dyslipidemia.

Hypertension is defined as blood pressure $>130 / 80 \mathrm{~mm} \mathrm{Hg}$

$2.4 \mathrm{~g} \mathrm{Na}^{+}=6 \mathrm{~g}$ salt $(\sim 1$ teaspoon) $1.5 \mathrm{~g} \mathrm{Na}^{+}=3.7 \mathrm{~g}$ salt $(\sim 2 / 3$ teaspoon $)$

The nutritional management of obesity and that of dyslipidemia are similar (Table 4).

When hypertension and dyslipidemia complicate prediabetes and diabetes, interventions are additive and intensified.

Follow-up evaluation is scheduled according to patient needs and local practice.
(8)

Maintain physical activity, meal plan, and MNT
(8)

Not at goals
Fig. 1 Transcultural medical nutrition algorithm for prediabetes and type 2 diabetes. AACE-American Association of Clinical Endocrinologists; ADA-American Diabetes Association; BMI—body mass index; DASH—Dietary Approaches to Stop Hypertension; FPG- fasting plasma glucose; $\mathrm{HbA}_{1 \mathrm{c}}$ - glycosylated hemoglobin $\mathrm{A}_{1 \mathrm{c}}$; IFG - impaired fasting glucose; IGT — impaired glucose tolerance; MNT_ medical nutrition therapy; OGTT — oral glucose tolerance test; PGplasma glucose; WC - waist circumference; WHR — waist-to-hip ratio review and subsequent modification or approval. Consensus recommendations were discussed at a second task force meeting held on June 17 to 18, 2011 in New York City. At that time, recommendations were critiqued, refined, and prepared for transcultural adaptation by an expanded task force team that included additional experts from Canada, India, and Spain. 
Table 1 Classification of body composition by BMI, WC, and disease risk for Caucasians

\begin{tabular}{|c|c|c|c|c|}
\hline & \multirow{2}{*}{$\begin{array}{l}\mathrm{BMI}, \\
\mathrm{kg} / \mathrm{m}^{2}\end{array}$} & \multirow{2}{*}{$\begin{array}{l}\text { Obesity } \\
\text { class }\end{array}$} & \multicolumn{2}{|c|}{ Disease risk } \\
\hline & & & $\begin{array}{l}\mathrm{WC}: \\
\mathrm{M} \leq 40 \text { in } \\
\mathrm{F} \leq 35 \text { in }\end{array}$ & $\begin{array}{l}W C: \\
M>40 \text { in } \\
F>35 \text { in }\end{array}$ \\
\hline Underweight & $<18.5$ & & & \\
\hline Normal & $18.5-24.9$ & & & \\
\hline Overweight & $25.0-29.9$ & & Increased & High \\
\hline \multirow[t]{2}{*}{ Obese } & $30.0-34.9$ & I & High & Very high \\
\hline & $35.0-39.9$ & II & Very high & Very high \\
\hline $\begin{array}{c}\text { Extremely } \\
\text { obese }\end{array}$ & $\geq 40$ & III & $\begin{array}{c}\text { Extremely } \\
\text { high }\end{array}$ & $\begin{array}{c}\text { Extremely } \\
\text { high }\end{array}$ \\
\hline
\end{tabular}

$B M I$ body mass index; $F$ female; $M$ male; $W C$ waist circumference (Adapted from: Bantle JP, Wylie-Rosett J, Albright AL, et al. Nutrition recommendations and interventions for diabetes: a position statement of the American Diabetes Association. Diabetes Care. 2008;31 Suppl $1:$ S61-78) [41••]

\section{Transculturalization Standards}

The transculturalization of CPGs addresses problems that arise when recommendations are considered for implementation in an environment beyond that of the sponsoring individuals or organization [45]. In regard to nutrition therapy, transcultural factors relate to genetic

Table 2 Classification of body composition by BMI, WC, and disease risk for Southeast Asians and Asian Americans

\begin{tabular}{lrlll}
\hline & BMI, & Obesity class & Disease risk \\
\cline { 3 - 4 } & $\mathrm{kg} / \mathrm{m}^{2}$ & & $\mathrm{WC}:$ & $\mathrm{WC}:$ \\
& & & $\mathrm{M} \leq 90 \mathrm{~cm}$ & $\mathrm{M}>90 \mathrm{~cm}$ \\
& & & $\mathrm{~F} \leq 80 \mathrm{~cm}$ & $\mathrm{~F}>80 \mathrm{~cm}$ \\
\hline Underweight & $<18.5$ & & \\
Normal & $18.5-22.9$ & Average & Average \\
Overweight & $23-24.9$ & I & Increased & High \\
Obese & $25.0-29.9$ & II & High & Very high \\
& & & Very high & Very high \\
Extremely obese & $\geq 30$ & III & Severe & Severe \\
\hline
\end{tabular}

$B M I$ body mass index; $F$ female; $M$ male; $W C$ waist circumference (Adapted from: Wildman RP, Gu D, Reynolds K, et al. Appropriate body mass index and waist circumference cutoffs for categorization of overweight and central adiposity among Chinese adults. Am J Clin Nutr. 2004;80:1129-36) [36]

(Adapted from: Appropriate body-mass index for Asian populations and its implications for policy and intervention strategies. WHO Expert Consultation. Lancet. 2004;363:157-63) [37]
Table 3 Physical activity guidelines for the management of diabetes

Intensity Physical activity

level

Low Patients should be encouraged to achieve an active

lifestyle and to avoid sedentary living, because physical activity and exercise provide many health benefits and facilitate glycemic control. Participation in any physical activity provides some health benefits

For substantial benefits:

$\geq 150 \mathrm{~min} /$ week of moderate-intensity activity, or

$\geq 75 \mathrm{~min} /$ week of vigorous-intensity aerobic activity, or

some combination of equivalent moderate/vigorous activity

Medium Aerobic activity should be performed in episodes of $\geq 10 \mathrm{~min}$ and preferably spread throughout the week

For additional, more extensive benefits:

$\geq 300 \mathrm{~min} /$ week of moderate-intensity activity, or

$\geq 150 \mathrm{~min} /$ week of vigorous-intensity aerobic activity, or

some combination of equivalent moderate/vigorous activity

additional health benefits are gained beyond this amount

High Moderate- or high-intensity resistance exercise training for all major muscle groups, as a separate modality from aerobic exercise, has been shown to increase muscle mass and strength, alter body composition, and improve glycemic control; therefore, it should be combined with aerobic activity in each individual $\geq 2$ days per week

Exercise should be undertaken only after cardiac clearance has been obtained

(Adapted from: US Department of Health and Human Services. 2008 Physical activity guidelines for Americans. 2008. http://www.health. gov/paguidelines/guidelines/summary.aspx. Accessed June 22, 2011) [35]

differences within a given population, food preferences, religious practices, socioeconomic status, and others. Attributes of the transculturalization process should include evidence-based methodology, scientific rigor, transparency, relevance, and authority commensurate with the original CPGs [30, 46-50]. To obtain the cooperation and acceptance of key regional stakeholders in the implementation of the CPGs, their participation in the transculturalization process is essential. Likewise, a mechanism to have regional experts train local stakeholders and then continue the iterative process is vital, along with a validation and evaluation process to further modify the CPGs, if needed [50, 51]. To accommodate patient opinion and choice, subjective patient preferences for health care interventions that are locally available should be considered [52-54], as well as cascades of alternative strategies for a specific action $[55,56]$ and patient aids to inform their decisions [53]. 
Table 4 AACE/ADA nutritional guidelines for the management of diabetes

Hypocaloric (weight loss) diet: $250-1000 \mathrm{kcal} / \mathrm{d}$ deficit

Target: decrease weight by $5 \%$ to $10 \%$ for overweight/obese, $15 \%$ for class 3 obesity

Target: decrease BMI by 2 to 3 units

Carbohydrates (preferably low-glycemic index): $45 \%$ to $65 \%$ daily energy intake and not less than $130 \mathrm{~g} / \mathrm{d}$ in patients on low calorie diet Protein: $15 \%$ to $20 \%$ daily energy intake

Dietary fat: $<30 \%$ daily energy intake

Saturated fat: $<7 \%$ daily energy intake

Cholesterol: $<200 \mathrm{mg} / \mathrm{d}$

Fiber: $25-50 \mathrm{~g} / \mathrm{d}$

Trans fats: minimize or eliminate

$A A C E$ American Association of Clinical Endocrinologists; $A D A$ American Diabetes Association; BMI body mass index

(Adapted from: National Guideline Clearinghouse. Guideline synthesis: Nutritional management of diabetes mellitus. 2009. http://www. guideline.gov.syntheses/synthesis.aspx?id+16430. Accessed June 22, 2011.) [40]

\section{Transculturalization of the Diabetes-Specific Nutrition Algorithm}

On July 8, 2011, clinical experts from the Philippines, Hong Kong, Indonesia, Malaysia, Taiwan, Singapore, and Thailand met in Taipei, Taiwan to learn about the tDNA and begin the process of adapting the algorithm to their territories. This transcultural group was composed of endocrinologists, dietitians, and primary care practitioners who represented the health care specialties serving the patient populations that were targeted for the adaptive process. During the meeting, participants received information on diabetes and lifestyle modification, nutrition therapy and related clinical outcomes, and tDNA program goals and objectives. A point-by-point review of the algorithm was undertaken to explore pathways, content, and supportive evidence and to elicit information for the cultural adaptation of the algorithm and related recommendations for Southeast Asian patients. Subcommittee meetings were subsequently held in Taiwan (July 18, 2011) and India (September 23, 2011) to explicitly populate the nodes of the algorithm and the cells of the calorie supplement/replacement matrix (Table 5) with specific transcultural information and recommendations for their respective regions. Companion articles in this issue of Current Diabetes Reports describe the adaptive process and related output [57, 58].

\section{Results}

An amalgam of the deliberations and conclusions of the expanded international task force is presented here,
Table 5 Diabetes-specific (glycemia targeted specialized) nutrition formulas for the management of prediabetes and diabetes

Overweight/ Use 2 to 3 diabetes-specific nutrition formulas ${ }^{\mathrm{a}}$ as part obese of a reduced calorie meal plan, as a calorie replacement for meal, partial meal, or snack (grade C; LOE 3)

Calorie goals:

$<250 \mathrm{lb}=1200$ to 1500 calories

$>250 \mathrm{lb}=1500$ to 1800 calories

Calories from diabetes-specific nutrition formulas

Calories from other healthy dietary source

Normal Uncontrolled 1 to 2 diabetes-specific nutrition formuweight diabetes las per day to be incorporated into a

$\mathrm{HbA}_{1 \mathrm{c}}>7 \%$ meal plan, as a calorie replacement for meal, partial meal, or snack (grade D; LOE 4)

Controlled Use of diabetes-specific nutrition formudiabetes las should be based on clinical judg$\mathrm{HbA}_{1 \mathrm{c}} \leq 7 \% \quad$ ment and individual assessment ${ }^{\mathrm{b}}$ (grade D; LOE 4)

Underweight Use diabetes-specific nutrition supplements ${ }^{\mathrm{c}} 1$ to 3 units/d per clinical judgment based on desired rate of weight gain and clinical tolerance (grade D; LOE 4)

LOE 1: data defined as conclusive results from prospective, randomized controlled trials that have large subject populations representative of the target population and results that are easily generalized to the target population. Data also include results from meta-analyses of randomized controlled trials, results from multicenter trials, and "all or none" evidence; LOE 2: data include conclusive results from individual randomized controlled trials that have limited subject numbers or target population representation; LOE 3: data include all other conclusive clinical findings from nonrandomized studies, studies without controls, and nonexperimental or observational studies. These data may require interpretation and, by themselves, are not compelling; LOE 4: data are defined as information based solely on experience or expert opinion and are not necessarily substantiated by any conclusive scientific data. Frequently, only LOE 4 data are available

${ }^{a}$ Diabetes-specific nutrition formulas are nutritional products used as replacement for meals, partial meals, or snacks to replace calories in the diet

${ }^{\mathrm{b}}$ Individuals who may have muscle mass and/or function loss and/or micronutrient deficiency may benefit from diabetes-specific nutrition supplements. Individuals who need support with weight maintenance and/or a healthy meal plan could benefit from diabetes-specific nutrition

${ }^{\mathrm{c}}$ Diabetes-specific nutrition supplements are complete and balanced nutritional products used in addition to a typical meal plan, to help promote increased nutritional intake

$H b A_{l c}$ glycosylated hemoglobin $\mathrm{A}_{1 c} ; L O E$ level of evidence

displaying the consensus composite template of the tDNA, which is being used in the transculturalization process. Adaptations will be considered in ongoing regional meetings until provincial versions of the algorithm are available for local implementation and validation throughout the world. 
Table 6 Criteria for bariatric surgery for the management of diabetes

$\mathrm{BMI} \geq 40 \mathrm{~kg} / \mathrm{m}^{2}$ (about $100 \mathrm{lb}$ overweight for men and $80 \mathrm{lb}$ for women) or

BMI $35-39.9 \mathrm{~kg} / \mathrm{m}^{2}$ and an obesity-related comorbidity, such as T2D, coronary heart disease, or severe sleep apnea

BMI 30-34.9 kg/m² under special circumstances

According to the International Diabetes Federation, bariatric surgery should be considered an alternative treatment option in patients with a BMI of $30-35 \mathrm{~kg} / \mathrm{m}^{2}$ when diabetes is not adequately controlled by a medical regimen and especially when there are cardiovascular disease risk factors

Consideration may be given to laparoscopic-assisted gastric banding in patients with T2D who have a BMI $>30 \mathrm{~kg} / \mathrm{m}^{2}$ or Roux-en-Y gastric bypass for patients with a BMI $>35 \mathrm{~kg} / \mathrm{m}^{2}$ to achieve at least shortterm weight reduction

And for each of the above:

Failure to achieve and sustain weight loss after attempts at lifestyle modification

Tolerable operative risks

Understanding of operation

Commitment to treatment and long-term follow-up

Acceptance of required lifestyle changes

$B M I$ body mass index; $T 2 D$ type 2 diabetes

(Adapted from: Weight-control Information Network-an information service of the National Institute of Diabetes and Digestive and Kidney Diseases (NIDDK). Bariatric surgery for severe obesity. 2009. http:// win.niddk.nih.gov/publications/gastric.htm. Accessed November 14, 2011) [38]

(Adapted from: International Diabetes Federation. Bariatric surgical procedures and interventions in the treatment of obese patients with type 2 diabetes: a position statement from the International Diabetes Federation Taskforce on Epidemiology and Prevention. http://www.idf. org/webdata/docs/IDF-Position-Statement-Bariatric-Surgery.pdf. Accessed June 27, 2011) [39]

(Adapted from: Handelsman Y, Mechanick JI, Blonde L, et al. American Association of Clinical Endocrinologists Medical Guidelines for Clinical Practice for developing a diabetes mellitus comprehensive care plan. Endocr Pract. 2011;17 Suppl 2:1-53) [15••]

\section{R1}

Diets, meals, and foods influence glycemic status and the risk of diabetic complications (grade A) [16, 59-61].

\section{R2}

MNT is important and should be implemented as an essential component of comprehensive management programs for all patients with T2D and prediabetes (grade A) [41••, 43, 62-67].

\section{R3}

Diets should be based on individual risk factors for impaired glucose tolerance, obesity, hypertension, and dyslipidemia (grade A) [64, 65, 67, 68].
Table 7 Antihypertensive diet: daily nutrient goals used in the DASH studies

\begin{tabular}{ll}
\hline Carbohydrate & $55 \%$ of calories \\
Total fat & $27 \%$ of calories \\
Protein & $18 \%$ of calories \\
Saturated fat & $6 \%$ of calories \\
Cholesterol & $150 \mathrm{mg}$ \\
Fiber & $30 \mathrm{~g}$ \\
Sodium & $1500 \mathrm{mg}$ \\
Potassium & $4700 \mathrm{mg}$ \\
Calcium & $1250 \mathrm{mg}$ \\
Magnesium & $500 \mathrm{mg}$ \\
\hline
\end{tabular}

DASH Dietary Approaches to Stop Hypertension

Based on a 2100 -calorie eating plan

(Adapted from: US Department of Health and Human Services. Your guide to lowering your blood pressure with DASH. NIH publication no. 06-408. 2006. http://www.nhlbi.nih.gov/health/public/heart/hbp/ dash/new_dash.pdf. Accessed June 22, 2011) [42]

\section{R4}

Cultural factors should guide the selection of local foods and meals to adhere with general nutrition recommendations from the AACE and ADA (grade D) [1, $41 \bullet \bullet, 43]$.

\section{R5}

Diabetes-specific formulas may be used for calorie replacement or supplementation as part of MNT (grade A) $[41 \bullet \bullet, 43,69 \bullet, 70,71]$. Prepared and packaged diabetesspecific formulas contain nutrients that are designed to facilitate glycemic control [69•]. Such nutrients include modified maltodextrin, fructose, fiber, soy protein, monounsaturated fatty acids, and antioxidants. Clinical studies have demonstrated improvements in glycemic profiles and reductions in disease complications among patients who consume prepared formula products as part of MNT. For patients with low body mass index (BMI) and/or insufficiency states, such as the elderly, caloric supplementation is helpful for weight gain, amelioration of nutritional deficiencies, and prevention of diabetic complications [69•, 72-75]. For patients with normal or elevated BMI, caloric replacement is helpful to achieve weight loss, greater metabolic control, and avoidance of subtle deficits of vitamins or other nutrients that can accompany simple calorie restriction [69•]. Intensification or reduction in the number of replacements and supplements is a stepped process based on clinical appraisals and modification of regimens to meet individual patient goals [73]. 
Table 8 Common international foods and glycemic indices

\begin{tabular}{|c|c|c|c|}
\hline $\begin{array}{l}\text { Carbohydrate } \\
\text { foods }\end{array}$ & $\begin{array}{l}\text { Glycemic } \\
\text { index }\end{array}$ & & $\begin{array}{l}\text { Glycemic } \\
\text { index }\end{array}$ \\
\hline Common foods & & Fruits & \\
\hline $\begin{array}{c}\text { White wheat } \\
\text { bread }\end{array}$ & 75 & Apple & 36 \\
\hline $\begin{array}{l}\text { Whole wheat } \\
\text { bread }\end{array}$ & 74 & Banana & 51 \\
\hline Multigrain bread & 53 & Dates & 42 \\
\hline Wheat roti & 62 & Mango & 51 \\
\hline Chapati & 52 & Orange & 43 \\
\hline Corn tortilla & 46 & Peaches & 43 \\
\hline White rice & 73 & Pineapple & 59 \\
\hline Brown rice & 68 & Watermelon & 76 \\
\hline Barley & 28 & Vegetables & \\
\hline Corn & 52 & Potato, boiled & 78 \\
\hline Spaghetti & 49 & $\begin{array}{l}\text { Potato, instant } \\
\text { mash }\end{array}$ & 87 \\
\hline Rice noodles & 53 & Potato, fried & 63 \\
\hline Udon noodles & 55 & Sweet potato & 63 \\
\hline Couscous & 65 & Carrots, boiled & 39 \\
\hline Dairy products & & Pumpkin, boiled & 64 \\
\hline Whole milk & 39 & Plantain & 55 \\
\hline Skim milk & 37 & Taro, boiled & 53 \\
\hline Soy milk & 37 & Vegetable soup & 48 \\
\hline Rice milk & 86 & Legumes & \\
\hline Ice cream & 51 & Chickpeas & 28 \\
\hline Yogurt & 41 & Kidney beans & 24 \\
\hline Cereals & & Lentils & 32 \\
\hline Cornflakes & 81 & Soy beans & 16 \\
\hline Rolled oat meal & 55 & Snacks & \\
\hline Instant oat meal & 79 & Chocolate & 40 \\
\hline Rice congee & 78 & Popcorn & 65 \\
\hline Muesli & 57 & Potato chips & 56 \\
\hline Millet porridge & 67 & Soda & 59 \\
\hline Biscuits & 69 & Rice crackers & 87 \\
\hline
\end{tabular}

Glycemic index (GI) ranks carbohydrates according to their effect on blood glucose levels. High GI $=\geq 70$; medium GI $=56-69$; low GI $=\leq 55$

(Adapted from: Atkinson FS, Foster-Powell K, Brand-Miller JC. International tables of glycemic index and glycemic load values: 2008. Diabetes Care. 2008;31:2281-3. 45. Baker R, Feder G. Clinical guidelines: where next? Int J Qual Health Care. 1997;9:399-404) [44]

\section{R6}

Geographic location and ethnocultural classifications should be used to tailor the algorithm for specific patient populations. Risk factors are the leading determinants of patient pathways and related recommendations; one or more risk factors identify patients who are more likely to experience disease progression and/or complications (grade A) [75-77]. Dietary modification can mitigate the following risk factors:
Table 9 Levels of substantiation and their respective numerical and semantic descriptors

$\begin{array}{lll} & 1 & \text { RCTs } \\ & 1 & \text { Meta-analyses of RCTs } \\ & 2 & \begin{array}{l}\text { Nonrandomized RCTs } \\ \text { Meta-analyses of } \\ \text { nonrandomized RCTs } \\ \text { Prospective cohort } \\ \text { studies }\end{array} \\ & 2 & \begin{array}{l}\text { Retrospective case- } \\ \text { control studies }\end{array} \\ & 2 & \text { Cross-sectional study } \\ & 2 & \begin{array}{l}\text { Surveillance study } \\ \text { Consecutive case series }\end{array} \\ \text { RCT randomized con- } & 3 & \text { Single case report } \\ \text { trolled trial } & 3 & \text { Expert consensus } \\ \text { (Adapted from: Mechanick } & 3 & \text { Expert opinion based on } \\ \text { J, Camacho PM, Cobin } & 4 & \text { experience } \\ \text { RH, et al. American } & 4 & \text { Theory-driven } \\ \text { Association of Clinical } & & \text { conclusions } \\ \text { Endocrinologists Pro- } & & \text { Experience-based } \\ \text { tocol for Standardized } & 4 & \text { information } \\ \text { Production of Clinical } & & \text { Review } \\ \text { Practice Guidelines- } & 4 & \\ \text { 2010 update. Endocr } \\ \text { Pract. 2010;16:270-83) }\end{array}$

T2D or prediabetes, excessive weight or obesity, hypertension, and dyslipidemia (grade A) [64, 65, 67].

\section{R7}

Anthropometric measures-BMI, waist circumference (WC), or WHR - should be used to assess body composition and risk of progression [41••]. Although each of these measures has merit in clinical practice, differences in values and interpretations arising from phenotypic and cultural differences among populations have confounded global standardization. Likewise, difficulty using some methods (eg, WHR) has created regional preferences in medical practice and influenced general recommendations. Consequently, $\mathrm{BMI}$ and $\mathrm{WC}$ were chosen as the preferred prioritized measures of body composition in the algorithm. Values for normal and abnormal composition can be adjusted via ethnocultural inputs for local applicability (grade B) [78, 79].

\section{$\mathrm{R} 8$}

Irrespective of patient risk factors, lifestyle intervention mandates professional counseling, physical activity, and healthy eating patterns consistent with current CPGs or evidence (grade A) [41••, 43]. Professional counseling may be impeded by local attitudes and costs as well as the lack of perceived value by patients who may be 
economically disadvantaged. Although both low-risk and high-risk patients should comply with these basic recommendations, high-risk patients should intensify their efforts according to their specific needs and conditions.

\section{R9}

A registered dietitian (RD) who is familiar with the components of MNT should be involved in patient management (grade B) [41••]. Long-term changes in behavior are difficult to achieve for many patients. To assist implementation, physicians should encourage and support patients through the behavior modification process. However, physicians are limited by time and experience in behavior modification techniques. Therefore, the use of other health care professionals with expertise in patient self-management may be necessary. Research has shown that lifestyle case management by RDs can improve health outcomes among patients with T2D [80, 81 • 82]. In cultures and regions (e.g., Hong Kong) where patients may oppose or decline nutrition consultation by health care providers who are not physicians, we encourage physicians to develop skills in nutrition medicine by participating in appropriate continuing medical education.

\section{$\mathrm{R} 10$}

Patients should be encouraged to lead an active lifestyle and avoid sedentary living, as physical activity and exercise independently confer health benefits and facilitate glycemic control (grade A) [35, 83-85]. Substantial benefit is achieved with $\geq 150$ min per week of moderate activity or $\geq 75 \mathrm{~min}$ per week of vigorous aerobic activity [83-86]. Resistance exercise training, as a separate modality from aerobic exercise, can increase muscle mass and improve glycemic control and should be combined with aerobic activity (grade D) [87]. Additional time spent on any physical activity can augment benefit and represents an intensification strategy for patients with higher risk stratification or those who do not achieve their goals with less intense activity.

\section{R11}

MNT was introduced in 1994 by the American Dietetic Association to better express the concept of therapeutic nutrition $[65,88]$. It consists of specific nutritional interventions that include assessment, counseling, and dietary modification, with and without specialized nutritional formulas for calorie supplementation or replacement [65]. Diabetes-specific MNT has been considered a cornerstone of diabetes treatment because it can improve glycemic profiles and reduce the risk of disease complications [65, 67, 89]. Formalized recommendations for T2D in the medical literature include the following: carbohydrates, preferentially from low-glycemic index foods, for $45 \%$ to $65 \%$ of daily energy intake and not less than $130 \mathrm{~g} /$ day in patients on low-calorie diets (grade D) [41••, 43, 90, 91]; fats for less than $30 \%$ of daily energy intake (grade D) $[41 \bullet \bullet, 43,90]$; saturated fat for less than $7 \%$ of daily energy intake (grade A) [41••, 43, 90, 92]; protein for $15 \%$ to $20 \%$ of energy intake and not less than $1 \mathrm{~g} / \mathrm{kg}$ in patients with normal kidney function (grade D) [41 ••, 43]; cholesterol restricted to less than $200 \mathrm{mg}$ daily (grade A) [41, 43, 90, 92]; trans fats eliminated or reduced to minimal intake (grade D) [41••, 43, 90, 92]; and fiber for 25 to 50 g daily (grade A) [41 ••, 43, 90].

\section{R12}

Overweight or obese patients should adhere to these guidelines and try to achieve a gradual weight loss of $5 \%$ to $10 \%$ by reducing caloric intake, for a total daily deficit of 250 to $1000 \mathrm{kcal}$ (grade A) [15••, 16, 17, 41••, 43, 70, 93, 94]. Patients with class 3 obesity should shed $15 \%$ of body

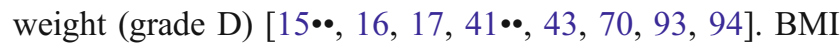
should be decreased by 2 to 3 units (grade D) [41 ••, 43, 70, $93,94]$. Any amount of weight loss is associated with metabolic benefits, even if clinical targets are not met.

\section{R13}

Bariatric surgery may be considered for patients with T2D and obesity who 1) fail to respond to lifestyle and pharmacologic interventions; 2) meet established criteria related to body composition, comorbidities, and surgical risk; and 3) commit to durable lifestyle changes and follow-up evaluations [95-98]. The recent statement by the International Diabetes Federation on criteria for bariatric surgery should be considered when making treatment decisions [39].

\section{R14}

Patients with T2D or prediabetes complicated by hypertension require further nutritional management. Sodium intake should already be limited to $1,500 \mathrm{mg}$ /day per recent recommendations provided by the Dietary Guidelines for Americans, 2010 (grade A) [99-102, 103•, 104]. The principles of the Dietary Approaches to Stop Hypertension (DASH) diet, particularly increasing the consumption of fresh fruits and vegetables, should also be incorporated into the patient's diet.

\section{R15}

Patients with lipid abnormalities must pay closer attention to fat intake based on their dyslipidemic profiles and may benefit from viscous fibers and plant sterols (grade A) [91, 
92, 105-111]. The reduction of simple sugars and alcohol is important for patients with hypertriglyceridemia.

\section{R16}

When multiple comorbidities exist in a patient with T2D or prediabetes, recommended interventions are applied simultaneously and at a higher level of intensity, but individual patient factors, such as potential for adherence, adverse effects, and dietary customs and practices, are also taken into account (grade D).

\section{R17}

Follow-up evaluations for all patients should occur at appropriate intervals depending on need (grade D). Assessments should include a history and physical examination (anthropometrics, blood pressure); blood chemistries (glucose, $\mathrm{HbA}_{1 \mathrm{c}}$, lipids, renal function, and liver enzymes depending on clinical status); and urinary microalbumin determination. Improvements in disease states based on follow-up assessments create an opportunity to diminish the intensity of interventions and to spare resources. Although deterioration of clinical status creates a need to increase the intensity of interventions, it also creates an opportunity to search for ways to improve care and possibly adherence.

\section{Discussion}

Within North America, the national prevalence of diabetes and prediabetes ranges from $10.1 \%$ in Mexico to $11.6 \%$ in Canada and $12.3 \%$ in the United States [1]. The global prevalence is significantly lower, at $6.6 \%$, but rates in the Arab countries are much higher at $13.4 \%$ (Oman) to $18.7 \%$ (United Arab Emirates) [1]. These figures reflect accurate estimates of the size of affected populations, but do not convey the complexities that underlie the epidemiology of the disease. Hidden behind these numbers are the details that illuminate the nature of the problem. Today, societies are heterogeneous not only in North America, but in many other places around the world. Continents, countries, states, municipalities, and even neighborhoods can be characterized by ethnicity, customs, mores, habits, and beliefs. All of these demographics influence personal choices that contribute to health or illness and the prevention or development and perpetuation of diabetes.

Health care providers must understand the culture of diabetes to effectively manage their patients with diabetes. Although general cultural sensitivity training is offered in medical school and through postgraduate activities, most practitioners are woefully deficient in the knowledge and skill to maneuver medically through the intricacies of a diverse patient population [112-115]. Clinical guidance rarely cites the cultural differences that truly matter in the delivery of health care. This may be especially true-and particularly important - with respect to diabetes, a disease that is intimately associated with lifestyles and foods. For these reasons, the international task force sought to identify and incorporate regional differences in genetic factors, diet, exercise, and culture into CPGs for nutrition therapy in T2D and prediabetes.

For example, based on clinical evidence, it was abundantly clear to the task force members that a principal cause of obesity and diabetes was the consumption of energy-rich or fast foods. Such foods are characterized by high concentrations of fats and refined carbohydrates with high glycemic indices. Describing foods in terms of composition, however, may limit comprehension and corrective action. Instead, citing examples that are culturally meaningful (e.g., fried white rice with pork drippings or quarter-pound cheeseburgers with french fries and soda) may be more relevant.

Assessing an individual for diabetes risk seems relatively straightforward until one realizes that Southeast Asians tend to develop the disease at a younger age and lower BMI. Disease management in Southeast Asian patients is also complicated by a greater prominence of postprandial hyperglycemia and renal complications.

Economics and education affect the likelihood that a health care intervention, regardless of its benefit, will be adopted and faithfully used by a particular segment of society. Task force members noted that the acceptance of dietitians or nutrition counselors, for instance, is low in Southeast Asia because the importance of such individuals is probably undervalued or misunderstood, not only by patients but occasionally by physicians, too. The cost and relative inaccessibility of these allied professionals may impede their participation in health care, especially when community resources are not available for targeted education. Moreover, broader education in the form of CPGs for comprehensive care of patients with diabetes as well as specific lifestyle interventions are needed worldwide, but guidance comes mostly from developed countries, especially Europe and North America, where interpretation of sophisticated recommendations is easier than in developing non-English-speaking nations. Couple this problem to a lack of familiarity with nutrition therapy in general and prepared liquid formulas in particular, and the likelihood of effective nutrition management is greatly reduced.

In response to these problems, we developed the tDNA. It has four major strengths: 1) simplicity that fosters not only an understanding of diabetes-specific nutrition therapy but also the cultural adaptation necessary for worldwide implementation; 2) incorporation of advice from national and international associations and respected publications; 3) inclusion of important clinical evidence and experience from multinational health care stakeholders who contributed to 
the developmental process; 4) openness to scientific and cultural adaptation.

Dietary and culinary habits within many diverse global communities must still be identified, and guidance must be further tailored along ethnic and cultural lines. To reach this end point within the tDNA program, diabetes and nutrition experts from around the world continue to be organized, familiarized with program goals, and invited to contribute to the transculturalization process. Adapted versions of the algorithm have already emerged for Southeast Asian and Asian Indian populations $[57,58]$. Implementation will require education initiatives and follow-up assessments to determine if clinical benefit is truly achieved. These activities are currently being planned within the tDNA program. If found to be successful in optimizing comprehensive diabetes care, the tDNA and related educational resources will be made available for widespread dissemination and worldwide implementation.

\section{Conclusions}

The algorithm presented here incorporates established standards used for CPG development, adaptation, and implementation. It is comprehensive and authoritative, yet brief and easy to use. Importantly, it is designed for simplicity and global cultural adaptation, or transculturalization. In large part, it conveys established clinical guidance from highly respected organizations for nutrition therapy and lifestyle management. It also references calorie augmentation or replacement with diabetes-specific liquid meals, a relatively novel addition to traditional nutrition therapy. It remains open to modification of content and context.

Acknowledgments We thank Science \& Medicine for editorial support and Abbott Nutrition for funding to develop this manuscript.

An abstract of this work was presented at the 71st Annual Meeting of the American Diabetes Association, June 24-28, 2011, San Diego, California. Additionally, abstracts related to certain methodologic aspects of this work were submitted to and/or accepted by the Asia Pacific Congress of Diabetes Education, the Asian Congress of Nutrition, the European Association for the Study of Diabetes, the European Society for Clinical Nutrition and Metabolism, and the Canadian Diabetes Association. These submitted and/or accepted abstracts focus on different aspects of the diabetes-specific nutrition algorithm presented in this work. The abstract submitted to the Asian Pacific Congress of Diabetes Education focuses on the application of the algorithm in culturally diverse populations, whereas the abstract submitted to the Asian Congress of Nutrition focuses on the applicability of the algorithm in Asian societies. The European Association for the Study of Diabetes and the European Society for Clinical Nutrition and Metabolism abstract submissions focus on the patient algorithm for nutrition therapy (PATH), which combines nutrition recommendations from major diabetes organizations and geographic and ethnocultural factors to optimize diabetes care. The abstract submitted to the Canadian Diabetes Association focuses on the transcultural diabetes nutrition algorithm, which is intended to supplement CPGs and provide evidence-based information on lifestyle modifications, including physical activity and nutrition interventions for patients with diabetes.
Disclosure Conflicts of interest: The development of this article was funded by Abbott Nutrition. The content was created and enriched solely by task force members through a process of ongoing literature searches, independent contributions and reviews, and group interactions for consensus. Other support may have been provided to task force members as indicated in the following statements. Caroline Apovian has received financial support from Amylin, Merck, Johnson \& Johnson, Arena, and Sanofi-Aventis; and research funding from Eli Lilly, Pfizer, Orexigen, Amylin, and MetaProteomics. Alexander Koglin Benchimol has served as a board member for Abbott, MSD, and Novo Nordisk; served as a consultant for Abbott, MSD, and Novo Nordisk; served as a speaker and developed educational presentations for Abbott, MSD, Novo Nordisk, Libbs, Sanofi-Aventis, and Torrent; and received funding for travel and accommodations from Abbott, MSD, Novo Nordisk, Libbs, Sanofi-Aventis, and Torrent. Peter H. Bisschop has received financial support for consultancy and research from Abbott Nutrition; also received funding for travel from Abbott Nutrition. Alexis Bolio-Galvis has nothing to disclose. Osama Hamdy has served as a consultant for Abbott Nutrition and a speaker for Amylin/Eli Lilly. Refaat A. Hegazi is employed by Abbott Nutrition; the material presented in this article is based on the best-known clinical evidence and is not affected by this financial relationship. David Jenkins has served as a consultant for Solae, Unilever, and Haine Celestial; served as an advisory board member for Herbalife International, Nutritional Fundamentals for Health, Pacific Health Laboratories, Metagenics/MetaProteomics, Bayer Consumer Care, and Orafti; received research funding from Solae, Unilever, Haine Celestial and Orafti; and received honorarium from Unilever. Miguel Leon Sanz has nothing to disclose. Albert E. Marchetti has received financial support for research and the development of educational materials from Eli Lilly, Takeda, GlaxoSmithKline, Bristol-Myers Squibb, and Abbott Nutrition International. Jeffrey Mechanick has received financial support for the development of educational presentations from Abbott Nutrition. He has received financial support for consultancy and for writing and reviewing the manuscript from Abbott Nutrition. He has received fees for participation in review activities such as data monitoring boards, statistical analysis, and end point committees from Abbott Nutrition International. $\mathrm{He}$ has received funding for travel and accommodations from Abbott Nutrition. Enrique Mendoza has received financial support for consultancy from Abbott Nutrition; He has received funding for travel and accommodations from Abbott Nutrition. Wayne Huey-Herng Sheu has received financial support for consultancy from Abbott Nutrition, Pfizer, GSK and Bayer. Patrizio Tatti received financial support for participation in review activities for Abbott Nutrition. He has received funding for travel from Abbott Nutrition. Man-Wo Tsang has nothing to disclose.

Open Access This article is distributed under the terms of the Creative Commons Attribution License which permits any use, distribution, and reproduction in any medium, provided the original author(s) and the source are credited.

\section{References}

Papers of particular interest, published recently, have been highlighted as:

\section{- Of importance \\ •• Of major importance}

1. International Diabetes Federation. IDF diabetes atlas. 4th ed. Brussels: International Diabetes Federation; 2009. 
2. The effect of intensive treatment of diabetes on the development and progression of long-term complications in insulin-dependent diabetes mellitus. The Diabetes Control and Complications Trial Research Group. N Engl J Med. 1993;329:977-86.

3. Intensive blood-glucose control with sulphonylureas or insulin compared with conventional treatment and risk of complications in patients with type 2 diabetes (UKPDS 33). UK Prospective Diabetes Study (UKPDS) Group. Lancet. 1998;352:837-53.

4. Effect of intensive therapy on the microvascular complications of type 1 diabetes mellitus. JAMA. 2002;287:2563-9.

5. Charlton-Menys V, Betteridge DJ, Colhoun H, et al. Targets of statin therapy: LDL cholesterol, non-HDL cholesterol, and apolipoprotein B in type 2 diabetes in the Collaborative Atorvastatin Diabetes Study (CARDS). Clin Chem. 2009;55:473-80.

6. Daly CA, Fox KM, Remme WJ, et al. The effect of perindopril on cardiovascular morbidity and mortality in patients with diabetes in the EUROPA study: results from the PERSUADE substudy. Eur Heart J. 2005;26:1369-78.

7. Esposito K, Giugliano D, Nappo F, Marfella R. Regression of carotid atherosclerosis by control of postprandial hyperglycemia in type 2 diabetes mellitus. Circulation. 2004;110:214-9.

8. Hansson L, Zanchetti A, Carruthers SG, et al. Effects of intensive blood-pressure lowering and low-dose aspirin in patients with hypertension: principal results of the Hypertension Optimal Treatment (HOT) randomised trial. HOT study group. Lancet. 1998;351:1755-62.

9. Nathan DM, Cleary PA, Backlund JY, et al. Intensive diabetes treatment and cardiovascular disease in patients with type 1 diabetes. N Engl J Med. 2005;353:2643-53.

10. Neil HA, DeMicco DA, Luo D, et al. Analysis of efficacy and safety in patients aged $65-75$ years at randomization: Collaborative Atorvastatin Diabetes Study (CARDS). Diabetes Care. 2006;29:2378-84.

11. Newman CB, Szarek M, Colhoun HM, et al. The safety and tolerability of atorvastatin $10 \mathrm{mg}$ in the Collaborative Atorvastatin Diabetes Study (CARDS). Diabetes Vasc Dis Res. 2008;5:177-83.

12. Ohkubo Y, Kishikawa H, Araki E, et al. Intensive insulin therapy prevents the progression of diabetic microvascular complications in Japanese patients with non-insulin-dependent diabetes mellitus: a randomized prospective 6-year study. Diabetes Res Clin Pract. 1995;28:103-17.

13. Stratton IM, Adler AI, Neil HA, et al. Association of glycaemia with macrovascular and microvascular complications of type 2 diabetes (UKPDS 35): prospective observational study. BMJ. 2000;321:405-12.

14. Turnbull F, Neal B, Ninomiya T, et al. Effects of different regimens to lower blood pressure on major cardiovascular events in older and younger adults: meta-analysis of randomised trials. BMJ. 2008;336:1121-3.

15. •- Handelsman Y, Mechanick JI, Blonde L, et al. American Association of Clinical Endocrinologists Medical Guidelines for Clinical Practice for developing a diabetes mellitus comprehensive care plan. Endocr Pract. 2011;17 Suppl 2:1-53. This is a principal source for algorithm content.

16. Knowler WC, Barrett-Connor E, Fowler SE, et al. Reduction in the incidence of type 2 diabetes with lifestyle intervention or metformin. N Engl J Med. 2002;346:393-403.

17. Tuomilehto J, Lindstrom J, Eriksson JG, et al. Prevention of type 2 diabetes mellitus by changes in lifestyle among subjects $>$ with impaired glucose tolerance. N Engl J Med. 2001;344:1343-50.

18. Scalzitti DA. Evidence-based guidelines: application to clinical practice. Phys Ther. 2001;81:1622-8.

19. Woolf SH, Grol R, Hutchinson A, et al. Clinical guidelines: potential benefits, limitations, and harms of clinical guidelines. BMJ. 1999;318:527-30.
20. Grol R, Dalhuijsen J, Thomas S, et al. Attributes of clinical guidelines that influence use of guidelines in general practice: observational study. BMJ. 1998;317:858-61.

21. • Mechanick JI, Camacho PM, Cobin RH, et al. American Association of Clinical Endocrinologists Protocol for Standardized Production of Clinical Practice Guidelines-2010 update. Endocr Pract. 2010;16:270-83.This is a primary methodology for algorithm development.

22. Burgers JS, Cluzeau FA, Hanna SE, et al. Characteristics of highquality guidelines: evaluation of 86 clinical guidelines developed in ten European countries and Canada. Int J Technol Assess Health Care. 2003;19:148-57.

23. Field MJ, Lohr KN. Guidelines for clinical practice: from development to use. Washington, D.C: Institute of Medicine, National Academy Press; 1992.

24. Shapiro DW, Lasker RD, Bindman AB, Lee PR. Containing costs while improving quality of care: the role of profiling and practice guidelines. Annu Rev Public Health. 1993;14:219-41.

25. Thomson R, Lavender M, Madhok R. How to ensure that guidelines are effective. BMJ. 1995;311:237-42.

26. Wollersheim H, Burgers J, Grol R. Clinical guidelines to improve patient care. Neth J Med. 2005;63:188-92.

27. Feder G, Eccles M, Grol R, et al. Clinical guidelines: using clinical guidelines. BMJ. 1999;318:728-30.

28. Davis DA, Taylor-Vaisey A. Translating guidelines into practice. A systematic review of theoretic concepts, practical experience and research evidence in the adoption of clinical practice guidelines. CMAJ. 1997;157:408-16.

29. Beller SE, Monatesti SJ. Problems with current practice guidelines and quality improvement (QI) programs and how to solve them. http://wellness.wikispaces.com/Problems+with+ Current+Practice + Guidelines + and + Quality + Improvement $+\% 28 \mathrm{QI}$ $\% 29+$ Programs + and + How + to + Solve + Them. Accessed November 142011.

30. Fervers B, Burgers JS, Haugh MC, et al. Adaptation of clinical guidelines: literature review and proposition for a framework and procedure. Int J Qual Health Care. 2006;18:167-76.

31. Cook R. Clinical algorithms and flow charts as representations of guideline knowledge. 2005. http://www.hinz.org.nz/journal/2005/ 09/Clinical-Algorithms-and-Flow-Charts-as-Representations-ofGuideline-Knowledge/923. Accessed October 172011.

32. Shiffman RN. Representation of clinical practice guidelines in conventional and augmented decision tables. J Am Med Inform Assoc. 1997;4:382-93.

33. Shiffman RN, Michel G, Essaihi A, Thornquist E. Bridging the guideline implementation gap: a systematic, document-centered approach to guideline implementation. J Am Med Inform Assoc. 2004;11:418-26.

34. Hahn KA, Ferrante JM, Crosson JC, et al. Diabetes flow sheet use associated with guideline adherence. Ann Fam Med. 2008;6:2358.

35. US Department of Health and Human Services. 2008 physical activity guidelines for Americans. 2008. http://www.health.gov/ paguidelines/guidelines/summary.aspx. Accessed June 22, 2011.

36. Wildman RP, Gu D, Reynolds K, et al. Appropriate body mass index and waist circumference cutoffs for categorization of overweight and central adiposity among Chinese adults. Am J Clin Nutr. 2004;80:1129-36.

37. Appropriate body-mass index for Asian populations and its implications for policy and intervention strategies. WHO Expert Consultation. Lancet. 2004;363:157-63.

38. Weight-control Information Network - an information service of the National Institute of Diabetes and Digestive and Kidney Diseases (NIDDK). Bariatric surgery for severe obesity. 2009. http://win.niddk.nih.gov/publications/gastric.htm. Accessed November 14, 2011. 
39. International Diabetes Federation. Bariatric surgical procedures and interventions in the treatment of obese patients with type 2 diabetes: a position statement from the International Diabetes Federation Taskforce on Epidemiology and Prevention. http:// www.idf.org/webdata/docs/IDF-Position-Statement-BariatricSurgery.pdf. Accessed June 27, 2011.

40. National Guideline Clearinghouse. Guideline synthesis: nutritional management of diabetes mellitus. 2009. http://www.guideline. gov.syntheses/synthesis.aspx?id+16430. Accessed June 22, 2011.

41. •• Bantle JP, Wylie-Rosett J, Albright AL, et al. Nutrition recommendations and interventions for diabetes: a position statement of the American Diabetes Association. Diabetes Care. 2008;31 Suppl 1:S61-78. This is a principal source for algorithm content.

42. US Department of Health and Human Services. Your guide to lowering your blood pressure with DASH. NIH publication no. 06-408. 2006. http://www.nhlbi.nih.gov/health/public/heart/hbp/ dash/new dash.pdf. Accessed June 22, 2011.

43. Rodbard HW, Blonde L, Braithwaite SS, et al. American Association of Clinical Endocrinologists medical guidelines for clinical practice for the management of diabetes mellitus. Endocr Pract. 2007;13 Suppl 1:1-68.

44. Atkinson FS, Foster-Powell K, Brand-Miller JC. International tables of glycemic index and glycemic load values: 2008. Diabetes Care. 2008;31:2281-3.

45. Baker R, Feder G. Clinical guidelines: where next? Int J Qual Health Care. 1997;9:399-404.

46. Development and validation of an international appraisal instrument for assessing the quality of clinical practice guidelines: the AGREE project. AGREE Collaboration. Qual Saf Health Care. $2003 ; 12: 18-23$

47. Graham ID, Harrison MB, Brouwers M. Evaluating and adapting practice guidelines for local use: a conceptual framework. In: Pickering S, Thompson J, editors. Clinical governance in practice. London: Harcourt; 2003. p. 213-29.

48. Graham ID, Harrison MB, Brouwers M, et al. Facilitating the use of evidence in practice: evaluating and adapting clinical practice guidelines for local use by health care organizations. J Obstet Gynecol Neonatal Nurs. 2002;31:599-611.

49. Atkins D, Best D, Briss PA, et al. Grading quality of evidence and strength of recommendations. BMJ. 2004;328:1490.

50. Fretheim A, Schunemann HJ, Oxman AD. Improving the use of research evidence in guideline development: 3. Group composition and consultation process. Health Res Pol Syst. 2006;4:15.

51. Harrison MB, Graham ID, Lorimer K, et al. Nurse clinic versus home delivery of evidence-based community leg ulcer care: a randomized health services trial. BMC Health Serv Res. 2008;8:243.

52. Chong C, Chen I, Naglie C, Krahn M. Do clinical practice guidelines incorporate evidence on patient preferences? Med Decis Making. 2007;27:E63-4.

53. van der Weijden T, Legare F, Boivin A, et al. How to integrate individual patient values and preferences in clinical practice guidelines? A research protocol. Implement Sci. 2010;5:10.

54. Schunemann HJ, Fretheim A, Oxman AD. Improving the use of research evidence in guideline development: 10 Integrating values and consumer involvement. Health Res Pol Syst. 2006;4:22

55. Oppenheim PI, Sotiropoulos G, Baraff LJ. Incorporating patient preferences into practice guidelines: management of children with fever without source. Ann Emerg Med. 1994;24:836-41.

56. Latoszek-Berendsen A, Talmon J, de Clercq P, Hasman A. With good intentions. Int J Med Inform. 2007;76 Suppl 3:S440-6.

57. Su H-Y, Tsang M-W, Huang S-Y, et al. Transculturalization of a diabetes-specific nutrition algorithm: Asian application. Curr Diab Rep. 2012, in press.

58. Joshi SR, Mohan V, Joshi SS, et al. Transcultural diabetes nutrition therapy algorithm: the Asian Indian application. Curr Diab Rep. 2012, in press.
59. Lindstrom J, Louheranta A, Mannelin M, et al. The Finnish Diabetes Prevention Study (DPS): lifestyle intervention and 3 -year results on diet and physical activity. Diabetes Care. 2003;26:3230-6.

60. Ratner R, Goldberg R, Haffner S, et al. Impact of intensive lifestyle and metformin therapy on cardiovascular disease risk factors in the diabetes prevention program. Diabetes Care. $2005 ; 28: 888-94$.

61. Gillies CL, Abrams KR, Lambert PC, et al. Pharmacological and lifestyle interventions to prevent or delay type 2 diabetes in people with impaired glucose tolerance: systematic review and meta-analysis. BMJ. 2007;334:299.

62. Fung TT, Rimm EB, Spiegelman D, et al. Association between dietary patterns and plasma biomarkers of obesity and cardiovascular disease risk. Am J Clin Nutr. 2001;73:61-7.

63. Liu E, McKeown NM, Newby PK, et al. Cross-sectional association of dietary patterns with insulin-resistant phenotypes among adults without diabetes in the Framingham Offspring Study. Br J Nutr. 2009;102:576-83.

64. Yu-Poth S, Zhao G, Etherton T, et al. Effects of the National Cholesterol Education Program's Step I and Step II dietary intervention programs on cardiovascular disease risk factors: a metaanalysis. Am J Clin Nutr. 1999;69:632-46.

65. Pastors JG, Warshaw H, Daly A, et al. The evidence for the effectiveness of medical nutrition therapy in diabetes management. Diabetes Care. 2002;25:608-13.

66. Imamura F, Lichtenstein AH, Dallal GE, et al. Generalizability of dietary patterns associated with incidence of type 2 diabetes mellitus. Am J Clin Nutr. 2009;90:1075-83.

67. Pastors JG, Franz MJ, Warshaw H, et al. How effective is medical nutrition therapy in diabetes care? J Am Diet Assoc. 2003;103:82731 .

68. Turner RC, Millns H, Neil HA, et al. Risk factors for coronary artery disease in non-insulin dependent diabetes mellitus: United Kingdom Prospective Diabetes Study (UKPDS: 23). BMJ. 1998;316:823-8.

69. - Tatti P, di Mauro P, Neri M, et al. Effect of a low-calorie highnutrition value formula on weight loss in type 2 diabetes mellitus. Mediterr J Nutr Metab. 2009; doi:10.1007/s12349-009-0050-7. This discusses evidence of the value of calorie replacement in the nutritional management of diabetes.

70. Elia M, Ceriello A, Laube H, et al. Enteral nutritional support and use of diabetes-specific formulas for patients with diabetes: a systematic review and meta-analysis. Diabetes Care. 2005;28:226779 .

71. Livesey G, Taylor R, Hulshof T, Howlett J. Glycemic response and health-a systematic review and meta-analysis: relations between dietary glycemic properties and health outcomes. Am J Clin Nutr. 2008;87:258S-68S.

72. Clinical guidelines on the identification, evaluation, and treatment of overweight and obesity in adults - the evidence report. National Institutes of Health. Obes Res. 1998;6 Suppl 2:51S-209S.

73. Turnbull PJ, Sinclair AJ. Evaluation of nutritional status and its relationship with functional status in older citizens with diabetes mellitus using the mini nutritional assessment (MNA) tool-a preliminary investigation. J Nutr Health Aging. 2002;6:185-9.

74. Benbow SJ, Hoyte R, Gill GV. Institutional dietary provision for diabetic patients. QJM. 2001;94:27-30.

75. Bonadonna RC, Cucinotta D, Fedele D, et al. The metabolic syndrome is a risk indicator of microvascular and macrovascular complications in diabetes: results from Metascreen, a multicenter diabetes clinic-based survey. Diabetes Care. 2006;29:2701-7.

76. Goldberg IJ. Clinical review 124: Diabetic dyslipidemia: causes and consequences. J Clin Endocrinol Metab. 2001;86:96571. 
77. Grossman E, Meserli F. Hypertension and diabetes. In: Fisman EZ, Tenenbaum A, editors. Cardiovascular diabetology: clinical, metabolic and inflammatory facets. Basel: Karger; 2008. p. 82106.

78. Janiszewski PM, Janssen I, Ross R. Does waist circumference predict diabetes and cardiovascular disease beyond commonly evaluated cardiometabolic risk factors? Diabetes Care. 2007;30:3105-9.

79. Lukaski HC. Methods for the assessment of human body composition: traditional and new. Am J Clin Nutr. 1987;46:537-56.

80. Franz MJ, Monk A, Barry B, et al. Effectiveness of medical nutrition therapy provided by dietitians in the management of non-insulin-dependent diabetes mellitus: a randomized, controlled clinical trial. J Am Diet Assoc. 1995;95:1009-17.

81. • Huang MC, Hsu CC, Wang HS, Shin SJ. Prospective randomized controlled trial to evaluate effectiveness of registered dietitian-led diabetes management on glycemic and diet control in a primary care setting in Taiwan. Diabetes Care. 2010;33:2339. This discusses international evidence of the value of nutritional management of diabetes.

82. Wolf AM, Conaway MR, Crowther JQ, et al. Translating lifestyle intervention to practice in obese patients with type 2 diabetes: Improving Control with Activity and Nutrition (ICAN) study. Diabetes Care. 2004;27:1570-6.

83. Pan XR, Li GW, Hu YH, et al. Effects of diet and exercise in preventing NIDDM in people with impaired glucose tolerance. The Da Qing IGT and Diabetes Study. Diabetes Care. 1997;20:53744.

84. Boule NG, Haddad E, Kenny GP, et al. Effects of exercise on glycemic control and body mass in type 2 diabetes mellitus: a meta-analysis of controlled clinical trials. JAMA. 2001;286:121827.

85. Nelson ME, Rejeski WJ, Blair SN, et al. Physical activity and public health in older adults: recommendation from the American College of Sports Medicine and the American Heart Association. Med Sci Sports Exerc. 2007;39:1435-45.

86. Albright A, Franz M, Hornsby G, et al. American College of Sports Medicine position stand. Exercise and type 2 diabetes. Med Sci Sports Exerc. 2000;32:1345-60.

87. Villareal DT, Apovian CM, Kushner RF, Klein S. Obesity in older adults: technical review and position statement of the American Society for Nutrition and NAASO, The Obesity Society. Am J Clin Nutr. 2005;82:923-34.

88. Identifying patients at risk: ADA's definitions for nutrition screening and nutrition assessment. Council on Practice (COP) Quality Management Committee. J Am Diet Assoc. 1994;94:8389 .

89. Mann JI, De Leeuw I, Hermansen K, et al. Evidence-based nutritional approaches to the treatment and prevention of diabetes mellitus. Nutr Metab Cardiovasc Dis. 2004;14:373-94.

90. Anderson JW, Randles KM, Kendall CW, Jenkins DJ. Carbohydrate and fiber recommendations for individuals with diabetes: a quantitative assessment and meta-analysis of the evidence. J Am Coll Nutr. 2004;23:5-17.

91. Jenkins DJ, Kendall CW, McKeown-Eyssen G, et al. Effect of a low-glycemic index or a high-cereal fiber diet on type 2 diabetes: a randomized trial. JAMA. 2008;300:2742-53.

92. Third Report of the National Cholesterol Education Program (NCEP) expert panel on detection, evaluation, and treatment of high blood cholesterol in adults (Adult Treatment Panel III) final report. Circulation. 2002;106:3143-421.

93. Caterson ID. Medical management of obesity and its complications. Ann Acad Med Singapore. 2009;38:22-7.

94. Klein S, Sheard NF, Pi-Sunyer X, et al. Weight management through lifestyle modification for the prevention and management of type 2 diabetes: rationale and strategies: a statement of the
American Diabetes Association, the North American Association for the Study of Obesity, and the American Society for Clinical Nutrition. Diabetes Care. 2004;27:2067-73.

95. Dixon JB, O'Brien PE, Playfair J, et al. Adjustable gastric banding and conventional therapy for type 2 diabetes: a randomized controlled trial. JAMA. 2008;299:316-23.

96. Mechanick JI, Kushner RF, Sugerman HJ, et al. American Association of Clinical Endocrinologists, The Obesity Society, and American Society for Metabolic \& Bariatric Surgery Medical guidelines for clinical practice for the perioperative nutritional, metabolic, and nonsurgical support of the bariatric surgery patient. Endocr Pract. 2008;14 Suppl 1:1-83.

97. Brolin RE. Bariatric surgery and long-term control of morbid obesity. JAMA. 2002;288:2793-6.

98. Pinkney J, Kerrigan D. Current status of bariatric surgery in the treatment of type 2 diabetes. Obes Rev. 2004;5:69-78.

99. Appel LJ, Moore TJ, Obarzanek E, et al. A clinical trial of the effects of dietary patterns on blood pressure. DASH Collaborative Research Group. N Engl J Med. 1997;336:1117-24.

100. Appel LJ, Brands MW, Daniels SR, et al. Dietary approaches to prevent and treat hypertension: a scientific statement from the American Heart Association. Hypertension. 2006;47:296308.

101. US Department of Agriculture and US Department of Health and Human Services. Dietary guidelines for Americans, 2010. 7th ed. Washington, DC: US Government Printing Office; 2010.

102. Appel LJ, Sacks FM, Carey VJ, et al. Effects of protein, monounsaturated fat, and carbohydrate intake on blood pressure and serum lipids: results of the OmniHeart randomized trial. JAMA. 2005;294:2455-64.

103. - Blumenthal JA, Babyak MA, Sherwood A, et al. Effects of the dietary approaches to stop hypertension diet alone and in combination with exercise and caloric restriction on insulin sensitivity and lipids. Hypertension. 2010;55:1199-205. This discusses evidence of the value of comprehensive lifestyle management that includes diet.

104. Sacks FM, Svetkey LP, Vollmer WM, et al. Effects on blood pressure of reduced dietary sodium and the Dietary Approaches to Stop Hypertension (DASH) diet. DASH-Sodium Collaborative Research Group. N Engl J Med. 2001;344:3-10.

105. Levine GN, Keaney Jr JF, Vita JA. Cholesterol reduction in cardiovascular disease. Clinical benefits and possible mechanisms. N Engl J Med. 1995;332:512-21.

106. Superko HR, Krauss RM. Coronary artery disease regression. Convincing evidence for the benefit of aggressive lipoprotein management. Circulation. 1994;90:1056-69.

107. Jenkins DJ, Jones PJ, Lamarche B, et al. Effect of a dietary portfolio of cholesterol-lowering foods given at 2 levels of intensity of dietary advice on serum lipids in hyperlipidemia: a randomized controlled trial. JAMA. 2011;306:831-9.

108. Grundy SM, Cleeman JI, Merz CN, et al. Implications of recent clinical trials for the National Cholesterol Education Program Adult Treatment Panel III guidelines. Circulation. 2004;110:22739.

109. Shepherd J, Cobbe SM, Ford I, et al. Prevention of coronary heart disease with pravastatin in men with hypercholesterolemia. West of Scotland Coronary Prevention Study Group. N Engl J Med. 1995;333:1301-7.

110. Buse JB, Ginsberg HN, Bakris GL, et al. Primary prevention of cardiovascular diseases in people with diabetes mellitus: a scientific statement from the American Heart Association and the American Diabetes Association. Circulation. 2007;115:114 26.

111. Randomised trial of cholesterol lowering in 4444 patients with coronary heart disease: the Scandinavian Simvastatin Survival Study (4S). Lancet. 1994;344:1383-9. 
112. Carrillo JE, Green AR, Betancourt JR. Cross-cultural primary care: a patient-based approach. Ann Intern Med. 1999;130:829 34.

113. Culhane-Pera KA, Reif C, Egli E, et al. A curriculum for multicultural education in family medicine. Fam Med. 1997;29:71923.
114. Green AR, Betancourt JR, Carrillo JE. Integrating social factors into cross-cultural medical education. Acad Med. 2002;77:193-7.

115. Like RC, Steiner RP, Rubel AJ. STFM core curriculum guidelines. Recommended core curriculum guidelines on culturally sensitive and competent health care. Fam Med. 1996;28:291-7. 